\title{
Mixed phenotype acute leukemia with PML-RARa positive: a case report and literature review
}

\author{
Xiaolong Zheng ${ }^{\dagger}$, Huafei Shen ${ }^{\dagger}$, Mingyu Zhu, Yuanfei Shi, Huanping Wang, Zhimei Chen, Xin Huang, \\ Yungui Wang, Jie Jin and Wanzhuo Xie
}

\begin{abstract}
Mixed phenotype acute leukemia (MPAL) is an uncommon type of leukemia. It is one kind of malignant clonal diseases that expresses more than one genealogical specific antigen simultaneously. Most MPAL patients are associated with clonal chromosomal abnormalities and molecular genetic changes, such as t(9;22) (q34;q11) and KMT2A (MLL) rearrangement. These specific abnormalities usually have important guiding significance in MPAL diagnosis, targeted therapy and prognosis judgment. In this paper, we reported a case of MPAL, T/myeloid (M5) with an unfrequent combination of PML-RARa positivity and $\mathrm{t}(15 ; 17)$. The treatment was successful with chemotherapy for both AML and ALL with daunorubicin, cytarabine (DA) and vincristine, prednisone (VP). We reported here this suggestive MPAL case of rare disease condition and effective treatment, in order to provide experience for the early diagnosis and treatment of similar patients.
\end{abstract}

Keywords: Acute leukemia, T/myeloid subtype, Mixed phenotype acute leukemia, PML-RARa, t(15;17), Acute biphenotypic leukemia, Case report

\section{Introduction}

With the development of cytogenetics and molecular biology, researchers have gradually strengthened their understanding of acute leukemia (AL). Morphology, immunology, cytogenetics, and molecular biology (MICM) are widely used in the world, which is not only of great significance to study the pathogenesis and biological characteristics of leukemia, but also of practical value to guide clinical treatment and prognosis judgment. According to its basic immunophenotype, AL is usually classified as acute myeloid leukemia (AML), acute B lymphoid leukemia (B-ALL), and acute T lymphoid leukemia (T-ALL). However, there is a type of ambiguous lineage,

\footnotetext{
*Correspondence: xiewanzhuo@zju.edu.cn

${ }^{\dagger}$ Xiaolong Zheng and Huafei Shen contributed equally to this work Department of Hematology, The First Affiliated Hospital, Zhejiang University School of Medicine, \#79 Qingchun Road, Hangzhou 310003, Zhejiang Province, People's Republic of China
}

which we call mixed phenotype acute leukemia (MPAL). MPAL is an extremely rare type, accounting for about $2-5 \%$ of all $\mathrm{AL}[1,2]$. It is characterized by the detection of at least two of three expression markers in myeloid lineage, $\mathrm{B}$ lineage and $\mathrm{T}$ lineage.

The current diagnosis of MPAL is mostly based on the relevant standards revised by World Health Organization (WHO) in 2016. Based on the updated WHO classification of hematological malignancies, MPAL can be divided into several subtypes including MPAL with $\mathrm{t}(9 ; 22)(\mathrm{q} 34.1 ; \mathrm{q} 11.2) ; \quad$ BCR-ABL1, MPAL with $\mathrm{t}(\mathrm{v} ; 11 \mathrm{q} 23.3)$; KMT2A rearranged, MPAL, B/myeloid, not otherwise specified (NOS) and MPAL, T/myeloid, NOS [3]. MPAL is one of highly heterogeneous malignancies, and the clonal origin of MPAL cells is still unclear. It may be derived from early hematopoietic stem cells and differentiate into myeloid and lymphoid leukemia cells during the development of AL. There is at present no unified treatment for this special type of leukemia. It is original author(s) and the source, provide a link to the Creative Commons licence, and indicate if changes were made. The images or other third party material in this article are included in the article's Creative Commons licence, unless indicated otherwise in a credit line to the material. If material is not included in the article's Creative Commons licence and your intended use is not permitted by statutory regulation or exceeds the permitted use, you will need to obtain permission directly from the copyright holder. To view a copy of this licence, visit http://creativecommons.org/licenses/by/4.0/. The Creative Commons Public Domain Dedication waiver (http://creativeco mmons.org/publicdomain/zero/1.0/) applies to the data made available in this article, unless otherwise stated in a credit line to the data. 
controversial on whether MPAL should be treated with a single chemotherapy or combined with chemotherapy for both lymphoid and myeloid leukemia, and whether bone marrow or peripheral blood stem cell transplantation is required. Thankfully, cell and molecular genetic abnormalities such as chromosomal translocations and gene mutations can be detected in most MPAL patients, which are of great significance for guiding the treatment and prognosis of MPAL patients [2, 4].

Here we reported an extremely rare case of MPAL, T/ AML(M5) with PML-RAR $\alpha$ rearrangement and $t(15 ; 17)$. We discussed his diagnosis, treatment process and outcome in detail, and combined with literature review, in order to provide experience for the early diagnosis and treatment of similar patients.

\section{Case report}

A 35-year-old man was admitted to the Department of Hematology, The First Affiliated Hospital, College of Medicine, Zhejiang University, in May 2020, with bleeding gums of 3-day duration. Physical examination showed scattered petechiae throughout the body. Routine laboratory tests revealed severe thrombocytopenia (platelets $\left.8 * 10^{9} / \mathrm{L}\right)$, abnormal white blood cell counts $\left(6.43 * 10^{9} / \mathrm{L}\right.$; $12.3 \%$ lymphocytes, $5.21 \%$ monocytes) and mild anemia (hemoglobin $100 \mathrm{~g} / \mathrm{L}$ ). Coagulation studies showed the international standardized ratio (INR) increased (1.18) and fibrinogen decreased $(1.58 \mathrm{~g} / \mathrm{L}$, normal range: 2.00-4.00 g/L), the others including thrombin time (TT), prothrombin time (PT) and activated partial thromboplastin time (APTT) were normal. D-Dimer was raised to $11,200 \mu \mathrm{g} / \mathrm{L} \mathrm{FEU} \mathrm{(normal} \mathrm{range:} 0-700 \mu \mathrm{g} / \mathrm{L} \mathrm{FEU}$ ). Lactate dehydrogenase (LDH) was slightly up to $385 \mathrm{U} / \mathrm{L}$ (normal range: 120-250 U/L).

\section{Morphology}

A bone marrow aspirate showed monocyte proliferation was significantly active, with $72 \%$ of primitive monocytes + immature monocytes and $14 \%$ of mature monocytes, while other lines was inhibited. Moreover, Cytochemical staining suggested that myeloperoxidase (MPO), sudan black B stain (SB), nonspecific esterase (NSE) and $\mathrm{NaF}$ inhibit test were all positive. Based on bone marrow appearance, it was considered as acute nonlymphoblastic leukemia, morphologically resembling AML-M5b (Fig. 1).

\section{Immunology}

Immunophenotype with flow cytometry analysis found the protocell population accounted for about $79 \%$ of nonerythroid cells, expressing CD117, CD34, CD33, CD13, CD19 (weak), CD7, CD123, CD14, CD4, CD2, CD1a,

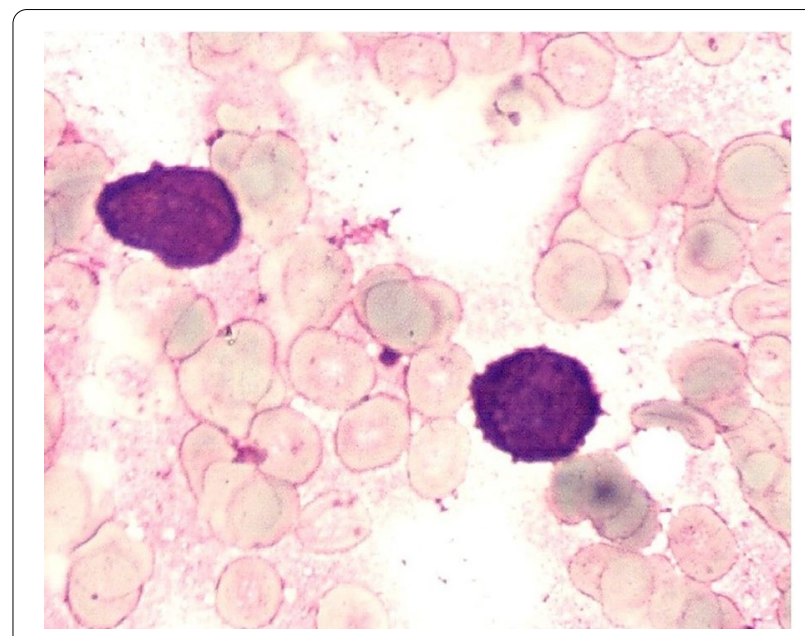

Fig. 1 Bone marrow aspiration revealed morphological findings compatible with AML-M5b

MPO, cyCD3, and CD56 (sectional), which suggested the possibility of mixed T/ myeloid leukemia (Fig. 2).

\section{Cytogenetics and molecular biology}

Chromosomal analysis with G-banded karyotype of bone marrow cells showed 46, XY, t(15;17)(q24;q21)[9]/46, XY[9] (Fig. 3). Fluorescence in situ hybridization (FISH) confirmed that PML/RAR $\alpha$ was positive (note: the quality of FISH image was not optimal, however). The positive rate of PML/RAR $\alpha$ short type was $39 \%$, while that of long type was negative. There was evidence of FLT3-ITD mutation and no evidence of IDH1, IDH2, CEBPA, c-kit or NPM1 mutations.

\section{Clinical course}

Based on his various auxiliary examinations, the diagnosis of MPAL was established. Then he was treated with daunorubicin, cytarabine (DA) and vincristine, prednisone (VP)(daunorubicin $120 \mathrm{mg}$ Day 1-3+cytarabine $100 \mathrm{mg}$ Day 1-5; vincristine $4 \mathrm{mg}$ Day 1, 8, $15+$ prednisone $10 \mathrm{mg}$ Day 1-21). The corresponding symptomatic support treatment also benefited the patient. The patient was subsequently treated with all-trans retinoic acid (ATRA) for maintenance therapy. There was no fever or bleeding during the whole treatment. After one course of chemotherapy, the patient's complete blood count (CBC) returned to be normal. Bone marrow examination revealed a primordial granulocyte ratio of less than $5 \%$. Thanks to the timely diagnosis of the disease and effective treatment regimens, the patient finally achieved complete remission (CR). At present, the patient has remained first CR during the over 3 months. 

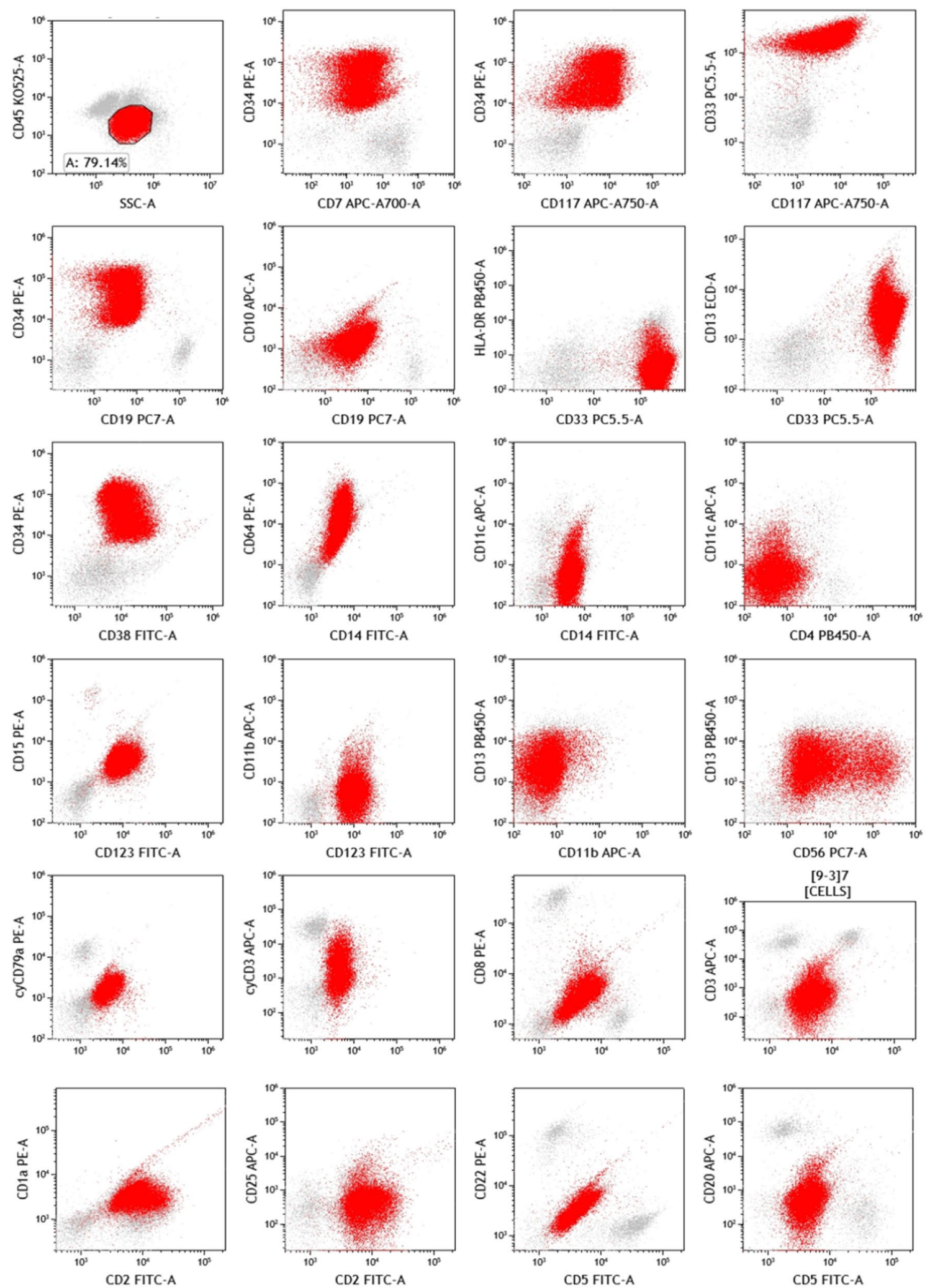

Fig. 2 Immunophenotype with flow cytometry analysis suggested the possibility of mixed T/ myeloid leukemia 


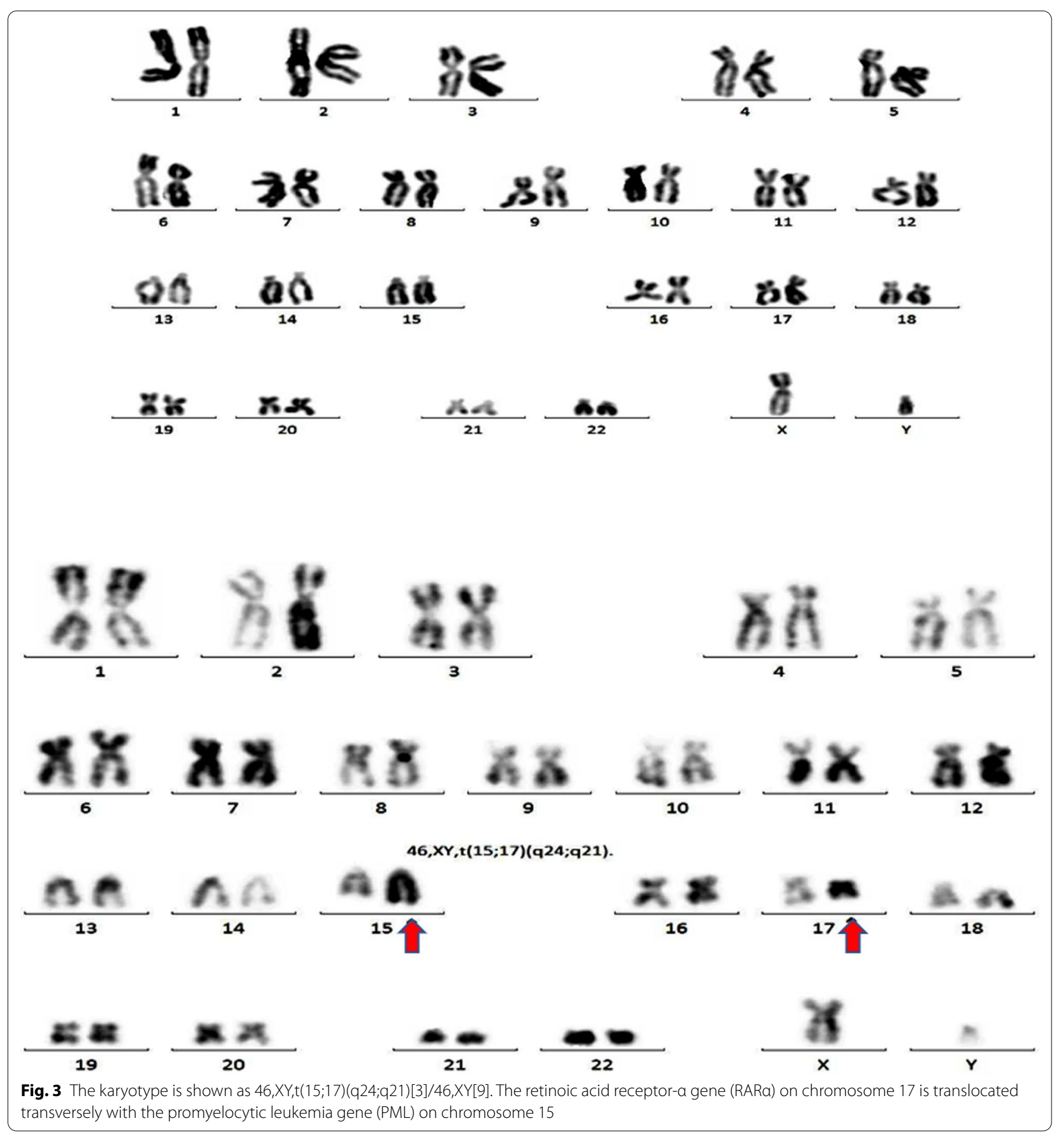

\section{Discussion}

MPAL has no specific chromosomal abnormalities. Owaidah et al. demonstrate that $68 \%$ of MPAL patients have clonal abnormalities, among which KMT2A translocation is the most common, followed by BCR-ABL [5, 6]. KMT2A rearrangement is more frequent in pediatric MPAL (especially infants), while BCR-ABL is more frequent in adults [7]. The case described herein is interesting because PML-RAR $\alpha$ rearrangement complicated with $\mathrm{t}(15 ; 17)$ in MPAL T/M cases is extremely uncommon. In general, PML-RAR $\alpha$ fusion and $t(15 ; 17)$ are regarded as highly specific for acute promyelocytic leukemia (APL). There is few cases of AML with PMLRAR $\alpha$ fusion and $t(15 ; 17)$ that were neither immunophenotypically nor morphologically consistent with 
APL [8]. To sum up, MPAL T/myeloid (M5) with PML$R A R \alpha$ positivity and $t(15 ; 17)$ is indeed quite rare.

The immunophenotype supported the diagnosis of MPAL T/M. In addition, we concerned that CD7 and CD34 were highly expressed in this case. CD7 is considered to be one of the $\mathrm{T}$ lymphoid-associated antigens, but it is not as specific as CD3. AML with CD7 high expression is generally connected with poor prognosis $[9,10]$. Expression of CD34 also predicted unsatisfactory outcome. Furthermore, some researchers demonstrated that the positive rate of CD34 in MPAL was as high as $84 \%$ [11-14]. However, individual case report cannot verify these conclusions. The stratification of MPAL risk level needs more cases series and analytical studies to develop.

FLT3 is one of the most common mutations in AML, whose occurrence is often associated with poor prognosis $[15,16]$. However, due to the rarity of MPAL, there are few studies on FLT3 mutation in MPAL. Zhang et al. indicated that ITD mutation was the dominant FLT3 mutation in MPAL patients [17]. Mutation in FLT3ITD was also detected in this case. Some researchers believed that stem cell transplantation was more beneficial than chemotherapy for AML patients with FLT3-ITD mutation [18]. However, whether that applies to MPAL patients is worth further study.

MPAL is characterized by unique clinical and biological characteristics, with higher incidence in adults than in children, which is generally associated with worse prognosis [4]. There may be several reasons for the poor prognosis. First, the leukemia stem cells of MPAL are primitive pluripotent progenitors, which replicate too slowly to be resistant to chemotherapy. Second, due to the transformable phenotype, MPAL cells are capable to adapt to therapy. Third, a part of MPAL can highly express resistance-conferring P-glycoprotein [19, 12]. Therefore, the choice of chemotherapy regimen has always been a major difficulty in MPAL treatment. Gerr $\mathrm{H}$, Rubnitz JE and their coworkers indicated that ALLdirected chemotherapy usually showed better outcome than AML-directed therapies in children. If the initial chemotherapy regimen was not effective, the conversion regimen could be chosen (from ALL-directed switch to AML-directed or vice versa). More than half of patients were able to achieve CR in the second regimen $[20,21]$. Nevertheless, some researchers revealed that combined AML/ALL type regimens were more effective than single regimen for adult patients. The CR rate of combined chemotherapy was the highest (71\%), followed by ALLdirected (64\%), and the lowest was AML-directed (33\%) [14]. Moreover, Zhang and his coworkers demonstrated that combined-type regimens or ALL-based protocols are effective for the treatment of adult MPAL [14] . As such, we managed the patient with combined chemotherapy for ALL and AML, which contributed to his achievement of CR.

In conclusion, we reported a pretty unfrequent case of MPAL T/M with PML/RAR $\alpha$ rearrangement and $t(15 ; 17)$. The outcome of this patient was markedly satisfactory with combined AML/ALL type regimens $(\mathrm{DA}+\mathrm{VP})$ and ATRA as well.

\begin{abstract}
Authors' contributions
WX designed the study and provided the feedback. XZ and HS drafted the manuscript and figures. MZ and YS collected the clinical data. HW, ZC, XH and YW collected the related literature. JJ edited the manuscript. All authors read and approved the final manuscript.
\end{abstract}

\section{Funding}

Not applicable.

Availability of data and materials

Not applicable.

\section{Ethics approval and consent to participate}

Informed consent was obtained in this case, and proto-

cols were approved by the scientific ethical committee of our hospital.

\section{Consent for publication}

Not applicable.

\section{Competing interests}

The authors declare that they have no competing interests.

Received: 25 December 2020 Accepted: 14 January 2021

Published online: 11 February 2021

\section{References}

1. Weinberg OK, Arber DA. Mixed-phenotype acute leukemia: historical overview and a new definition. Leukemia. 2010;24(11):1844-51.

2. Yan L, Ping N, Zhu M, Sun A, Xue Y, Ruan C, et al. Clinical, immunophenotypic, cytogenetic, and molecular genetic features in 117 adult patients with mixed-phenotype acute leukemia defined by WHO-2008 classification. Haematologica. 2012;97(11):1708-12.

3. Arber DA, Orazi A, Hasserjian R, Thiele J, Borowitz MJ, Le Beau MM, et al. The 2016 revision to the World Health Organization classification of myeloid neoplasms and acute leukemia. Blood. 2016;127(20):2391-405.

4. Matutes E, PickI WF, Van't Veer M, Morilla R, Swansbury J, Strobl H, et al. Mixed-phenotype acute leukemia: clinical and laboratory features and outcome in 100 patients defined according to the WHO 2008 classification. Blood. 2011;117(11):3163-71.

5. Owaidah TM, Al Beihany A, lqbal MA, Elkum N, Roberts GT. Cytogenetics, molecular and ultrastructural characteristics of biphenotypic acute leukemia identified by the EGIL scoring system. Leukemia. 2006;20(4):620-6.

6. Alexander TB, Gu Z, lacobucci I, Dickerson K, Choi JK, Xu B, et al. The genetic basis and cell of origin of mixed phenotype acute leukaemia. Nature. 2018:562(7727):373-9.

7. Manola KN. Cytogenetic abnormalities in acute leukaemia of ambiguous lineage: an overview. Br J Haematol. 2013;163(1):24-39.

8. Virchis A, Massey E, Butler T, Devaraj P, Wright F, Secker-Walker L, et al. Acute myeloblastic leukaemias of FAB types M6 and M4, with cryptic PML/RARalpha fusion gene formation, relapsing as acute promyelocytic leukaemia M3. Br J Haematol. 2001;114(3):551-6.

9. Cross AH, Goorha RM, Nuss R, Behm FG, Murphy SB, Kalwinsky DK, et al. Acute myeloid leukemia with T-lymphoid features: a distinct biologic and clinical entity. Blood. 1988;72(2):579-87.

10. Kita K, Miwa H, Nakase K, Kawakami K, Kobayashi T, Shirakawa S, et al. Clinical importance of CD7 expression in acute myelocytic leukemia. 
The Japan Cooperative Group of Leukemia/Lymphoma. Blood. 1993;81(9):2399-405.

11. Killick S, Matutes E, Powles RL, Hamblin M, Swansbury J, Treleaven $\mathrm{JG}$, et al. Outcome of biphenotypic acute leukemia. Haematologica. 1999;84(8):699-706.

12. Legrand O, Perrot JY, Simonin G, Baudard M, Cadiou M, Blanc C, et al Adult biphenotypic acute leukaemia: an entity with poor prognosis which is related to unfavourable cytogenetics and P-glycoprotein overexpression. Br J Haematol. 1998;100(1):147-55.

13. Hanson CA, Abaza M, Sheldon S, Ross CW, Schnitzer B, Stoolman LM. Acute biphenotypic leukaemia: immunophenotypic and cytogenetic analysis. Br J Haematol. 1993;84(1):49-60.

14. Zhang $Y$, Wu D, Sun $A$, Qiu H, He G, Jin Z, et al. Clinical characteristics, biological profile, and outcome of biphenotypic acute leukemia: a case series. Acta Haematol. 2011;125(4):210-8.

15. Metzeler KH, Herold T, Rothenberg-Thurley M, Amler S, Sauerland MC, Görlich D, et al. Spectrum and prognostic relevance of driver gene mutations in acute myeloid leukemia. Blood. 2016;128(5):686-98

16. Khaled S, Al Malki M, Marcucci G. Acute myeloid leukemia: biologic, prognostic, and therapeutic insights. Oncology (Williston Park). 2016;30(4):318-29.

17. Yu Z, Yang HZ, Fang HW, Mingyu HW, Hong HL, Panxiang HC, et al. Mutation characteristics of FLT3 gene and clinical efficacy of tyrosine kinase inhibitor in mixed phenotype acute leukemia. Journal of Leukemia and Lymphoma. 2020;29(01):37-40.

18. Fleischmann M, Schnetzke U, Schrenk KG, Schmidt V, Sayer HG, Hilgendorf I, et al. Outcome of FLT3-ITD-positive acute myeloid leukemia: impact of allogeneic stem cell transplantation and tyrosine kinase inhibitor treatment. J Cancer Res Clin Oncol. 2017;143(2):337-45.

19. Charles NJ, Boyer DF. Mixed-phenotype acute leukemia: diagnostic criteria and pitfalls. Arch Pathol Lab Med. 2017;141(11):1462-8.

20. Gerr H, Zimmermann M, Schrappe M, Dworzak M, Ludwig WD, Bradtke $J$, et al. Acute leukaemias of ambiguous lineage in children: characterization, prognosis and therapy recommendations. Br J Haematol. 2010;149(1):84-92.

21. Rubnitz JE, Onciu M, Pounds S, Shurtleff S, Cao X, Raimondi SC, et al. Acute mixed lineage leukemia in children: the experience of St. Jude Children's Research Hospital. Blood. 2009;113(21):5083-9.

\section{Publisher's Note}

Springer Nature remains neutral with regard to jurisdictional claims in published maps and institutional affiliations.
Ready to submit your research? Choose BMC and benefit from:

- fast, convenient online submission

- thorough peer review by experienced researchers in your field

- rapid publication on acceptance

- support for research data, including large and complex data types

- gold Open Access which fosters wider collaboration and increased citations

- maximum visibility for your research: over 100M website views per year

At BMC, research is always in progress.

Learn more biomedcentral.com/submissions 